\title{
Increased Temporal Cortex ER Stress Proteins in Depressed Subjects Who Died by Suicide
}

Christopher Bown, B.Sc., Jun-Feng Wang, M.D., Ph.D., Glenda MacQueen, M.D., Ph.D., and L. Trevor Young, M.D., Ph.D.

Regulation of ER stress proteins, such as the 78-kilodalton glucose regulated protein (GRP78) by chronic treatment with mood stabilizing drugs suggests that this family of proteins may be involved in the pathophysiology of mood disorders. Indeed, increased levels of GRP78, GRP94, and calreticulin, a third member of the ER stress protein family, were found in temporal cortex of subjects with major depressive disorder who died by suicide compared with controls and subjects who died by other means. No such differences were found in subjects with other psychiatric disorders such as bipolar disorder or schizophrenia. These data suggest a potential role for ER stress proteins in severe depression that merits further study.

[Neuropsychopharmacology 22:327-332, 2000] (c) 2000 American College of Neuropsychopharmacology. Published by Elsevier Science Inc.
KEY WORDS: GRP78; GRP94; Calreticulin; Depression; Suicide; Antidepressants; Anticonvulsants

Current theories of the pathophysiology of mood disorders suggest that prolonged increases in glucocorticoid levels, likely the result of prolonged environmental stress, lead to biochemical changes in cortical and limbic neurons that leave individuals vulnerable to depression (Duman et al. 1997). A number of studies have found evidence of neuronal atrophy and loss of hippocampal neurons in response to stress (Magarinos et al. 1996; Uno et al. 1989; Sapolsky et al. 1985), and a report of reduced hippocampal volumes in elderly patients with histories of depression suggests that analogous processes may occur in individuals with depression (Sheline et al. 1996).

From the Mood Disorders Program, McMaster University, Hamilton, Ontario, Canada.

Address correspondence to: L. Trevor Young, M.D., Ph.D., McMaster University, Department of Psychiatry and Behavioural Neurosciences, HSC-4N77A, 1200 Main Street West, Hamilton, Ontario, Canada, L8N $3 Z 5$.

Received April 29, 1999; revised July 12, 1999; accepted July 16, 1999.
Some models of mood disorders (Hyman and Nestler 1996; Post 1992) have attempted to incorporate the notion of compensatory processes into an understanding of the pathophysiologic changes that occur in patients with mood disorders, but few studies have tested these notions empirically (Post 1992). Part of the difficulty has been identifying neuroprotective mechanisms that may be of relevance for mood disorders.

Recently, we found that treatment with the mood stabilizing drugs, valproate and carbamazepine, increased expression of the 78-kilodalton glucose-regulated protein (GRP78) (Wang et al. 1999). GRP78 is a member of the ER stress protein family that includes GRP94 and calreticulin, all of which function as $\mathrm{Ca}^{2+}$ binding proteins and molecular chaperones to assist in the regulation of protein folding (Gething 1997). These proteins have neuroprotective properties, are induced by seizures and ischemic damage, and may be involved in Alzheimer's disease pathology (Yu et al. 1999; Lowenstein et al. 1994; Hamos et al. 1991).

Increased expression of ER stress proteins by mood stabilizing drugs suggest that these proteins may be in- 
volved in the pathophysiology of mood disorders, perhaps as compensatory factors induced in response to stress-related neuronal damage. Further evidence for a role of neuroprotective proteins in mood disorders comes from recent reports of increased Bcl-2 levels, another neuroprotective anti-apoptotic factor, after treatment with mood stabilizers (Chen et al. 1999; Chen and Chuang 1999). To test the hypothesis that ER stress proteins may be important in the pathophysiology of mood disorders, we measured GRP78, GRP94 and calreticulin in postmortem samples of patients with mood disorders, schizophrenia and nonpsychiatric controls.

\section{METHODS}

Postmortem brain tissue was obtained from the Stanley Foundation Neuropathology Consortium (4 groups of $n=$ 15 age- and sex-matched subjects, i.e., subjects with bipolar disorder (BD), subjects with Major Depressive Disorder (MDD), subjects with schizophrenia (SCZ), and non-psychiatric, non-neurologic comparison subjects) (Johnston et al. 1997). Details on dissection and clinical characteristics have been previously published (Dowlatshahi et al. 1998, 1999).

Briefly, all medical records for psychiatric cases were reviewed by two psychiatrists. Diagnosis was determined according to DSM-IV criteria. If there was disagreement about the diagnosis, a third psychiatrist read the records. If a diagnosis could not be established, a family member was then interviewed. All interviewed relatives were first degree except for two (one aunt and one father-in-law). Similarly, a clinical interview was performed with a family member of each normal control. Cause of death, substance abuse history, medications at time of death and lifetime intake of antipsychotics was available for all subjects (details for MDD subjects shown in Table 1).

Sections were cut from coronal blocks. All sections are cut perpendicular to the anterior-posterior axis of the brain. All cortical layers were included as was the underlying white matter. The thickness of underlying white matter in the block was not predetermined and therefore could have varied between subjects. The sections obtained were approximately one gram, and further dissected into $50 \mathrm{mg}$ sections to include a full thickness section.

Total protein was prepared using a whole cell extraction protocol of $50 \mathrm{mg}$ of temporal cortex tissue (Brodmann Areas 20 and 21) (Dowlatshahi et al. 1998; Wang et al. 1999). Briefly, cells were sonicated in $3 \mathrm{v}$. of 150 $\mathrm{mM} \mathrm{NaCl}, 15 \mathrm{mM} \mathrm{MgCl} 2,1 \mathrm{mM}$ EGTA, $50 \mathrm{mM}$ Hepes$\mathrm{KOH}, 10 \%$ glycerol, $1 \%$ Triton $\mathrm{X}-100$ supplemented with $0.2 \mathrm{mM}$ phenylmethylsulfonyl fluoride (PMSF), and $1 \mu \mathrm{g} / \mathrm{ml}$ pepstatin. Following sonication cells were centrifuged at $14,000 \mathrm{~g}$ for $20 \mathrm{~min}$ at $4^{\circ} \mathrm{C}$ and the supernatants used. Immunoblotting was carried out following the method of Wang et al. (1999) using $30 \mu \mathrm{g}$ of protein per lane. Equal loading and transfer was detected

Table 1. Cause of Death and Treatment Information of Subjects with MDD

\begin{tabular}{|c|c|c|c|c|c|}
\hline Age/Sex & $\begin{array}{c}\text { Postmortem } \\
\text { Interval } \\
\text { (hours) }\end{array}$ & $\begin{array}{l}\text { Antidepresant/ } \\
\text { Mood Stabilizer } \\
\text { Medications at } \\
\text { Time of Death }\end{array}$ & $\begin{array}{c}\text { Other } \\
\text { Medications }\end{array}$ & $\begin{array}{l}\text { Cause of } \\
\text { Death }\end{array}$ & $\begin{array}{c}\text { Alcohol/ } \\
\text { Substance } \\
\text { Abuse }\end{array}$ \\
\hline $32 / \mathrm{F}$ & 47 & $\mathrm{TCA}^{b, c}$ & $\mathrm{BDZ}$ & Suicide & None \\
\hline $44 / \mathrm{F}$ & 32 & $\mathrm{TCA}^{b, c}, \mathrm{SSRI}^{c}$ & $\mathrm{BDZ}$ & Suicide & None \\
\hline $46 / \mathrm{M}$ & 26 & None $\mathrm{e}^{a, b}$ & $\begin{array}{l}\text { BDZ, } \\
\text { diphenhydramine }\end{array}$ & Suicide & None \\
\hline $51 / \mathrm{M}$ & 26 & Nefazadone $^{a}$ & Hydroxyzine & Suicide & Past \\
\hline $39 / \mathrm{M}$ & 23 & None $^{a, b}$ & None & Suicide & Current \\
\hline $42 / \mathrm{M}$ & 7 & None $e^{a, b}$ & None & Suicide & None \\
\hline $30 / \mathrm{F}$ & 33 & $\mathrm{TCA}^{b, c}, \mathrm{SSRI}^{c}$ & BDZ & Suicide & None \\
\hline $53 / \mathrm{F}$ & 40 & $\mathrm{Li}$, trazadone & None & $\begin{array}{r}\text { Acute alcohol } \\
\text { intoxication }\end{array}$ & Current \\
\hline $65 / \mathrm{M}$ & 19 & None $^{b, c}$ & Phenytoin & Cardiac & None \\
\hline $52 / \mathrm{M}$ & 12 & None & None & Cardiac & None \\
\hline $42 / F$ & 25 & SSRI, Li & None & Cardiac & None \\
\hline $56 / \mathrm{M}$ & 23 & SSRI & None & Cardiac & None \\
\hline $56 / \mathrm{F}$ & 28 & SSRI & BDZ, buspirone & Pulmonary & None \\
\hline $43 / \mathrm{M}$ & 43 & TCA & None & Cardiac & Current \\
\hline $47 / \mathrm{M}$ & 28 & Nefazadone, SSRI & None & Cardiac & None \\
\hline
\end{tabular}

Abbreviations: TCA, tricyclic antidepressant; SSRI, selective serotonin reuptake inhibitor; Li, lithium; BDZ, benzodiazepine.

${ }^{a}$ Antidepressant/mood stabilizer treatment was confirmed with toxicological data obtained from urine.

${ }^{b}$ Antidepressant/mood stabilizer treatment was confirmed with toxicological data obtained from blood.

${ }^{c}$ Antidepressant/mood stabilizer treatment was confirmed with toxicological data obtained from brain. 
A
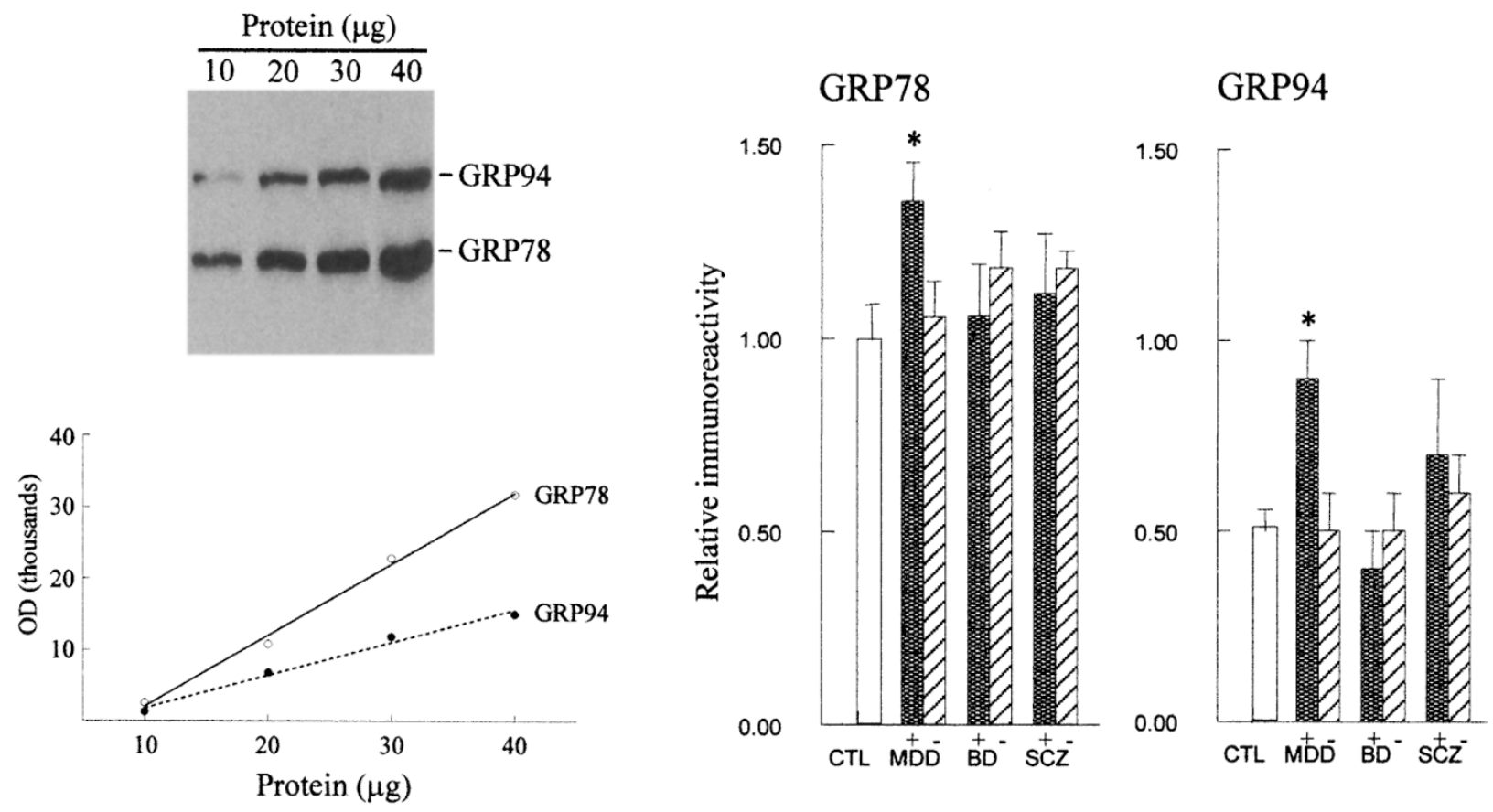

B

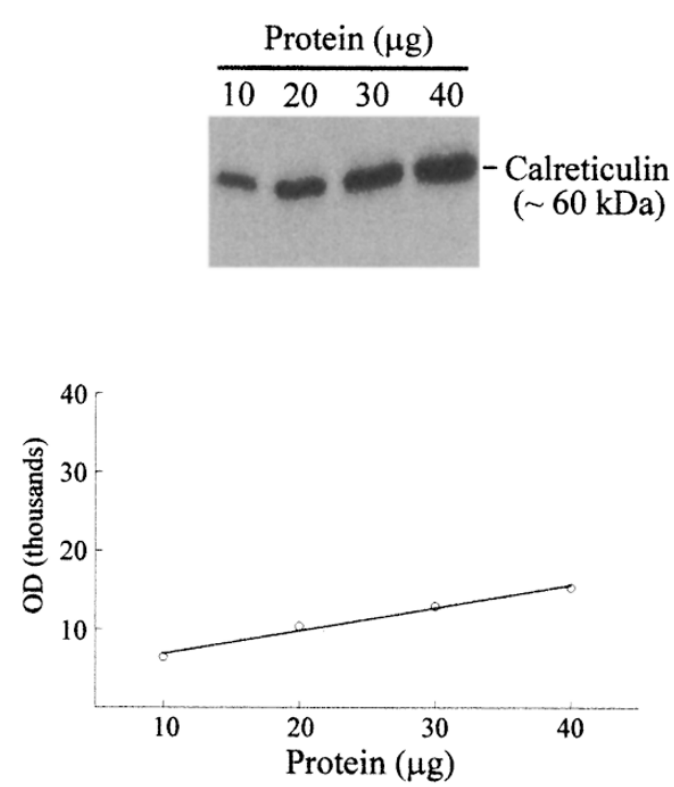

\section{Calreticulin}

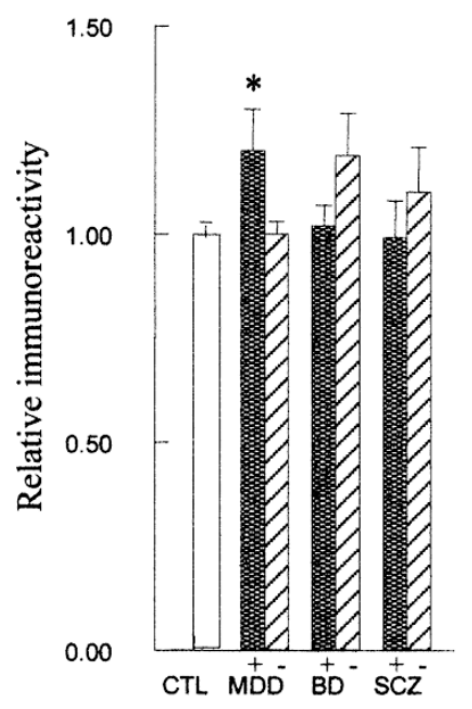

Figure 1. Effect of diagnosis and suicide on GRP78, GRP94, and calreticulin immunoreactivity in postmortem temporal cortex. Immunoblots represent linear ranges of protein used for standardization. Ten to $40 \mu \mathrm{g}$ of whole cell extract from temporal cortex from one healthy comparison subject was run on every gel. A standard curve relating optical density to protein concentration from one healthy comparison subject was constructed for each blot and used to determine the relative immunoreactivity for each subject. MDD suicide ( + ) subjects $(n=7)$ had significantly higher GRP78 (A), GRP94 (A), and calreticulin (B) immunoreactivities compared to controls (CTL, $n=15)$ and MDD non-suicide $(-)$ subjects $(n=8)$. Both BD $(n=9$ for suicide) and SCZ ( $n=4$ for suicide) subjects showed no increase in immunoreactivity in any of the proteins compared to the CTL group or non-suicide subjects (BD, $n=6$; SCZ, $n=11$ ). Autoradiograms were quantified by densitometry. Results are mean \pm S.E.M. ${ }^{*} p<.05$ significantly different from controls and non-suicide MDD subjects by ANOVA. 
using Ponseau S staining. Tissue samples from one healthy comparison subject were run on every gel (10$40 \mu \mathrm{g}$ ) to ensure assays were performed within the linear range and to allow comparisons across blots (Figure 1).

A standard curve relating optical density to protein concentration from the one comparison subject was constructed for each blot. The optical density for $30 \mu \mathrm{g}$ of protein, as determined from the standard curve, was used to determine the relative immunoreactivity for each of the samples. All blots were repeated and tested blind to diagnosis. If greater than $20 \%$ variability was found between the two relative immunoreactivity values for each subject, the sample was repeated. Primary monoclonal antisera for GRP78, which cross-reacts with GRP94 (1:2500 dilution) and polyclonal antisera for calreticulin (1:25,000 dilution) were obtained from Stressgen Biotechnologies (Victoria, B.C.). Secondary antibodies, goat anti-mouse IgG conjugated to horseradish peroxidase diluted 1:2500 (Santa Cruz Biotechnology, Santa Cruz, CA) for GRP78/94 and goat anti-rabbit IgG diluted 1:25,000 for calreticulin (Upstate Biotechnologies, Lake Placid, NY) were used, followed by detection with enhanced chemiluminescence (ECL) (Amersham, Arlington Heights, IL). Immunoreactive bands were quantified by densitometry using the SCID image analysis system (ImageExperts, Oakville, ON). Statistical analysis was conducted using one-way analysis of variance (ANOVA).

\section{RESULTS}

Subject characteristics for the MDD group are shown in Table 1. Figure 1 shows that immunoblotting with GRP78/94 or calreticulin antisera yielded immunoreactive bands at 78, 94, and $60 \mathrm{kDa}$, previously identified as GRP78, GRP94, and calreticulin, respectively. To determine if age, sex, and postmortem delay affected GRP78, GRP94 and calreticulin protein expression, we examined protein levels across these variables in the entire sample. There were no significant effects of age, sex or postmortem delay on GRP78, GRP94, and calreticulin immunoreactivity in the temporal cortex ( $p>.05$ in all cases). No significant diagnostic differences $(p>.05)$ were found in levels of GRP78, GRP94, and calreticulin when comparing $\mathrm{BD}, \mathrm{MDD}$, and $\mathrm{SCZ}$ subjects with control subjects. However, we found significantly increased levels of GRP78 ( $\mathrm{F}=3.50, \mathrm{df}=2,27, p=.045), \mathrm{GRP} 94(\mathrm{~F}=4.41, \mathrm{df}$ $=2,27, p=.022)$, and calreticulin $(\mathrm{F}=4.52, \mathrm{df}=2,27, p$ $=.020$ ) in the MDD group when comparing subjects who suicided with controls or with those who died by other means (Figure 1). GRP78, GRP94, and calreticulin levels were increased by $35 \%, 64 \%$, and $20 \%$, respectively, over control subjects and $28 \%, 69 \%$, and $20 \%$ over nonsuicide MDD subjects.
Although it cannot be known for certain in all subjects whether the treatment history reflects the actual medication taken by the patient at the time of death, we found no differences comparing subjects who were treated with either antidepressants, anticonvulsants, or lithium at the time of death compared to those who were not on any of these pharmacological agents ( $p>.05$ in all cases).

\section{DISCUSSION}

In the present study we found significantly increased levels of GRP78, GRP94, and calreticulin in temporal cortex of subjects with MDD who died by suicide compared to those who did not. It is unlikely that these differences are the result of suicide itself because no differences were found in patients with BD or SCZ who died by suicide. Furthermore, it does not appear that subjects who died by suicide had different patterns of pharmacologic treatment or greater rates of substance abuse to account for the increased levels in the ER stress proteins (see Table 1), and given the consistency of the pattern across the three proteins, it is very unlikely that this is a spurious finding.

Induction of ER stress proteins in MDD may be an attempt to compensate for the toxic effect of prolonged stress and glucocorticoid release on vulnerable brain regions such as the temporal cortex. In support of this hypothesis is the fact that dysregulation of the HPA axis, which controls glucocorticoid levels is particularly common in severe forms of depression and in those patients with suicidal ideation or attempts (Lopez et al. 1997).

Given the nature of the postmortem tissue used in this study it is not possible to know whether MDD patients who died by suicide were more severely ill at the time of death, or had differences in response or exposure to antidepressants. Since we controlled for other risk factors for suicide such as age, gender and substance abuse (Mann et al. 1999), differences in illness severity or response to treatment between the two groups seems to be likely explanations. Whatever the reason for these differences, upregulation of ER stress proteins in temporal cortex of MDD subjects who commit suicide may be important for several reasons.

Since calreticulin modulates glucocorticoid responsive gene expression (Michalak et al. 1996), it is interesting to speculate that this may have been an attempt to compensate for high levels of circulating glucocorticoids on these vulnerable brain regions. Moreover, since studies have shown that increased expression of ER stress proteins prevents $\mathrm{Ca}^{2+}$ depletion from the ER and protects against cellular damage and death (Lievremont et al. 1997; Liu et al. 1997, 1998; Yu et al. 1999), it is possible that an elevation of these proteins in this subgroup of patients may have been an attempt to compen- 
sate for these neuropathologic changes in this patient group. Indeed, several recent studies are suggestive of cellular loss and glial changes in cortical regions of patients with MDD, which may be correlated with severity of illness (Ongur et al. 1998; Rajkowska et al. 1999).

These results need to be interpreted with caution as the functional significance of these differences needs to be established as well as measurement of these proteins in other brain regions. Although clinical information on these subjects appears to be comprehensive and detailed, we cannot rule out the possibility that an undetermined clinical variable contributed to the pattern of results. Nonetheless, the present findings, even with a relatively small sample size suggest that further study of the role of ER stress proteins in MDD and its treatment are worthwhile.

\section{ACKNOWLEDGMENTS}

This work was supported by the Theodore and Vada Stanley Foundation (L.T.Y.) and the Medical Research Council of Canada (LTY). Dr. L. T. Young is a career scientist of the Ontario Ministry of Health. Dr. G. MacQueen is a fellow of the Canadian Psychiatric Research Foundation. Postmortem brains were donated by the Stanley Foundation Brain Consortium courtesy of Drs. Llewellyn B. Bigelow, Juraj Cervenak, Mary M. Herman, Thomas M. Hyde, Joel E. Kleinman, Jose D. Paltan, Robert M. Post, E. Fuller Torrey, Maree J. Webster, and Robert H. Yolken.

\section{REFERENCES}

Chen G, Zeng WZ, Yuan PX, Huang LD, Jiang YM, Zhao ZH, Manji HK (1999): The mood-stabilizing agents lithium and valproate robustly increase the levels of the neuroprotective protein bcl-2 in the CNS. J Neurochem 72:879-882

Chen RW, Chuang DM (1999): Long term lithium treatment suppresses p53 and Bax expression but increases Bcl-2 expression. A prominent role in neuroprotection against excitotoxicity. J Biol Chem 5:6039-6042

Dowlatshahi D, MacQueen GM, Wang JF, Young LT (1998): Increased temporal cortex CREB concentrations and antidepressant treatment in major depression. Lancet 352:1754-1755

Dowlatshahi D, MacQueen GM, Wang JF, Reiach JS, Young LT (1999): G-protein coupled cAMP signalling in postmortem brain of subjects with mood disorders: effects of diagnosis, suicide and treatment at the time of death. J Neurochem 73:1121-1126

Duman RS, Heninger GR, Nestler EJ (1997): A molecular and cellular theory of depression. Arch Gen Psychiatry 54:597-606

Gething M-J (1997): Guidebook to Molecular Chaperones and Protein-folding Catalysts. Oxford, Oxford University Press

Hamos JE, Oblas B, Pulaski-Salo D, Welch WJ, Bole DG,
Drachman DA (1991): Expression of heat shock proteins in Alzheimer's disease. Neurology 41:345-350

Hyman SE, Nestler EJ (1996): Initiation and adaptation: a paradigm for understanding psychotropic drug action. Am J Psychiatry 153:151-162

Johnston NL, Cerevnak J, Shore AD, Torrey EF, Yolken RH (1997): Multivariate analysis of RNA levels from postmortem human brains as measured by three different methods of RT-PCR: Stanley Neuropathology Consortium. J Neurosci Meth 77:83-92

Lievremont J-P, Rizutto R, Hendershot L, Meldolesi J (1997): $\mathrm{BiP}$, a major chaperone protein of the endoplasmic reticulum lumen, plays a direct and important role in the storage of the rapidly exchanging pool of $\mathrm{Ca}^{2+}$. J Biol Chem 272:12003-12009

Liu H, Bowes RC $3^{\text {rd }}$, van de Water B, Sillence C, Nagelkerke JF, Stevens JL (1997): Endoplasmic reticulum chaperones GRP78 and calreticulin prevent oxidative stress, $\mathrm{Ca}^{2+}$ disturbances, and cell death in renal epithelial cells. J Biol Chem 272:21751-21759

Liu H, Miller E, van de Water B, Stevens JL (1998): Endoplasmic reticulum stress proteins block oxidant-induced $\mathrm{Ca}^{2+}$ increases and cell death. J Biol Chem 273:1285812862

Lopez JF, Vazquez DM, Chalmers DT, Watson SJ (1997): Regulation of 5-HT receptors and the hypothalamicpituitary-adrenal axis. Implications for the neurobiology of suicide. Ann NY Acad Sci 836:106-134

Lowenstein DH, Gwinn RP, Seren MS, Simon RP, McIntosh TK (1994): Increased expression of mRNA encoding calbindin-D28K, the glucose-regulated proteins, or the 72 kDA heat-shock protein in three models of acute CNS injury. Mol Brain Res 22:299-308

Magarinos AM, McEwan BS, Flugge G, Fuchs E (1996): Chronic psychosocial stress causes apical dendritic atrophy of hippocampal CA3 pyramidal neurons in subordinate tree shrews. J Neurosci 16:3534-3540

Mann JJ, Waternaux C, Haas GL, Malone KM (1999): Toward a clinical model of suicidal behavior in psychiatric patients. Am J Psychiatry 156:181-189

Michalak M, Burns K, Andrin C, Mesaeli N, Jass GH, Busaan JL, Opas M (1996): Endoplasmic reticulum form of calreticulin modulates glucocorticoid-sensitive gene expression. J Biol Chem 271:29436-29445

Ongur D, Drevets WC, Price JL (1998): Glial reduction in the subgenual prefrontal cortex in mood disorders. Proc Natl Acad Sci USA 95:13290-13295

Post RM (1992): Transduction of psychosocial stress into the neurobiology of recurrent affective disorder. Am J Psychiatry 149:999-1010

Rajkowska G, Miguel-Hidalgo JJ, Wei J, Dilley G, Pittman SD, Meltzer HY, Overholser JC, Roth BL, Stockmeier CA (1999): Morphometric evidence for neuronal and glial prefrontal cell pathology in major depression. Biol Psychiatry 45:1085-1098

Sapolsky RM, Krey LC, McEwen BS (1985): Prolonged glucocorticoid exposure reduces hippocampal neuron number: Implications for aging. J Neurosci 5:1222-1227

Sheline YI, Wang PW, Gado MH, Csernansky JG, Vannier 
MW (1996): Hippocampal atrophy in recurrent major depression. Proc Natl Acad Sci USA 93:3908-3913

Uno H, Tarara R, Else JG, Suleman MA, Sapolsky RM (1989): Hippocampal damage associated with prolonged and fatal stress in primates. J Neurosci 9:1705-1711

Wang JF, Bown C, Young LT (1999): Differential display PCR reveals novels targets for the mood stabilizing drug valproate including the molecular chaperone, glucose-regulated protein 78. Mol Pharmacol 55:521-527

Yu Z, Luo H, Fu W, Mattson MP (1999): The endoplasmic reticulum stress-responsive protein GRP78 protects neurons against excitotoxicity and apoptosis: suppression of oxidative stress and stabilization of calcium homeostasis. Exp Neurol 155:302-314 